\title{
Chapter 14 \\ Building Quality from the Ground Up in a Cancer Center
}

\author{
Arslan Babar and Alberto J. Montero
}

\section{Background}

In a landmark article in 1966 [1], Avedis Donabedian, one of the pioneers of quality improvement in medicine, proposed a structural framework for assessing quality in healthcare. According to this framework, quality in healthcare is evaluated on three different dimensions: structure, process, and outcome. This framework remains relevant today and is still an extremely useful model for assessing quality in medicine.

Structure, in Donabedian's model, is the context of where and how care is delivered and paid for. This includes facilities, equipment, people who provide the care, and the ways care is paid for. Process involves the interactions between patients and providers along the entire continuum of care-in other words, the processes by which providers and hospital systems can ensure the safety and well-being of patients. Outcome, the third dimension, is what most think about when they consider quality in health care - that is, the end result or effect of the care on the health status of individuals and entire populations. Example would be unplanned hospital readmissions, or five-year survival rates in patients with breast cancer.

In later work, Donabedian expanded his quality framework into the "seven pillars of quality": efficacy, effectiveness, efficiency, optimality, acceptability, legitimacy, and equity $[2,3]$. The three components and seven pillars have served as the backbone of quality improvement in subsequent decades. A useful summary of

\footnotetext{
A. Babar

Taussig Cancer Institute, Cleveland Clinic Foundation, Cleveland, OH, USA

e-mail: Babara@ccf.org
}

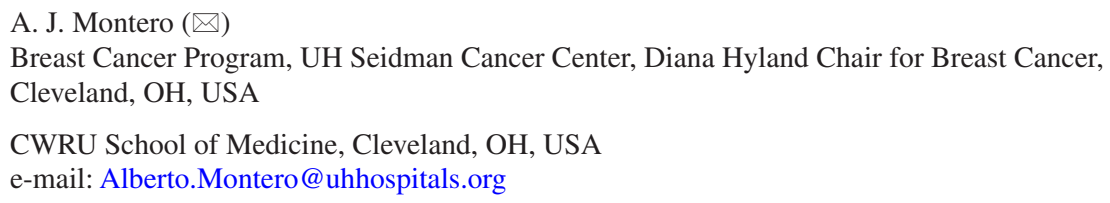


Donabedian's work was published in NEJM in 2016, on the fiftieth anniversary of his seminal article [4].

Reports from the Institute of Medicine (IOM) in the United States in 1990, 1999, and 2001 adopted Donabedian's framework in their analyses and their recommendations for implementation. The first of these reports, Medicare: A Strategy for Quality Assurance [5], called for the creation of a Medicare Program to Assure Quality (MPAQ) and largely employed Donabedian's structure-process-outcome framework. The second report, Ensuring Quality Cancer Care [6], applied improvement principles specifically to cancer care, creating a twenty-first century framework for quality measurement in oncology, building on Donabedian's original triad of structure, process, and outcome. The 2001 report, Crossing the Quality Chasm [7], meanwhile, highlighted six core aims (similar to Donabedian's seven pillars) for quality in health care: safe, effective, patient-centered, timely, efficient, and equitable. Subsequent reports from IOM/NAM have continued to build on this work [8].

Quality improvement in cancer care is especially urgent today, given the rising global incidence of cancer and soaring drug costs. The annual cost of care for a cancer patient is four times that for a noncancer patient in the United States [9]. The cost of cancer care is rising, and one major study has predicted a U.S. cancer survivorship expenditure growth rate of $1.99 \%$ over the period from 2015 to 2030 (\$183 billion to $\$ 246$ billion, inclusive of care and drug costs) [10]. Globally, the burden of cancer is expected to rise. The World Health Organization's (WHO) International Agency for Research on Cancer predicts a global increase in new cancer cases from 18.1 to 29.5 million from 2018 to 2040 (2.25\% yearly growth rate), if rates remain constant, due only to population growth and demographic trends [11]. The increase is heterogeneous with respect to location and cancer type. For example, from 2013 to 2035 , colorectal cancer cases are expected to increase in Australia by $59 \%$ and in the United States by $28 \%$, while the number of deaths globally is expected to increase by $60 \%$ for colon cancer and $71 \%$ for rectal cancer [12].

The updated IOM report recognized the challenges faced by cancer care delivery. According to the IOM report, the number of adults older than 65 is rapidly increasing. Because the majority of cancer diagnoses and deaths occur in this demographic, the incidence of cancer is expected to increase $45 \%$ by 2030 . Taken together, the rapid increase in the geriatric population, steady increase in the incidence of agerelated cancers, and rapidly evolving treatment landscape underscore the importance of multidisciplinary cancer care. Consequently, a cancer center model appears to be the best model for ensuring high-quality cancer care in a patient-centered manner.

High-quality cancer care is characterized by the following features [13]:

- Prioritizes the safety of patients, through creation of processes that minimize harm and medical errors.

- Creates a culture that promotes evidence-based care and continuous improvement of current practices.

- Maintains a patient-centered focus, and factor in personal and cultural needs. 


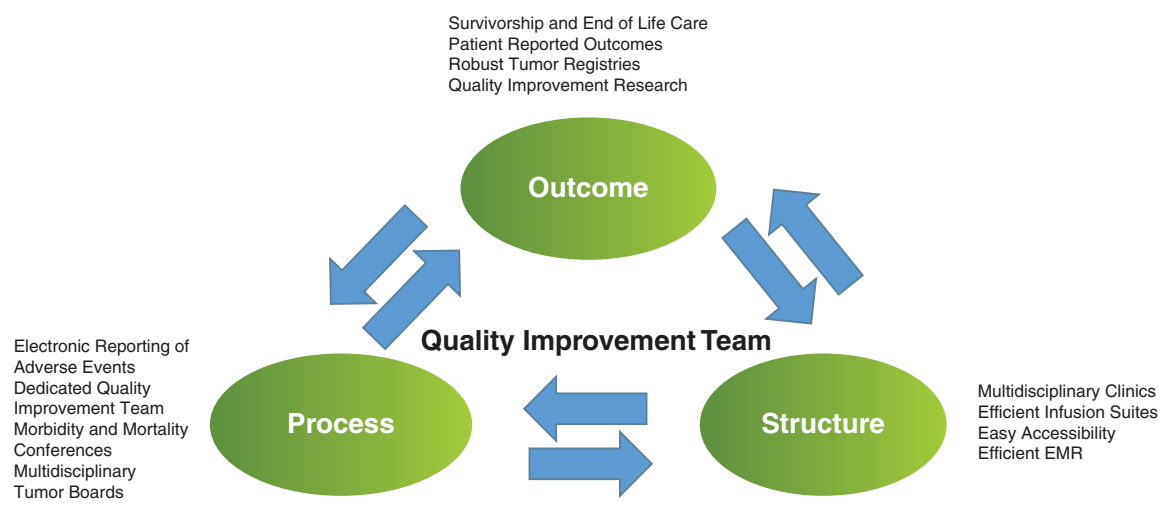

Fig. 14.1 Proposed quality of care model for cancer centers

- Practices time efficiency, and minimize any delays that would be harmful to the patient and/or the caregivers.

- Avoids any form of waste, including supplies, equipment, ideas, and human resources.

- Ensures fairness and equity among all patients without discrimination.

Toward this end, when thinking about how to build a high-quality cancer center, Donabedian's model is particularly useful in considering these essential components (Fig. 14.1).

\section{Structure}

In Donabedian's model, structure refers to the context of where the care is delivered. Cancer care is complex and multidisciplinary. Therefore, a structural feature of quality cancer care is to have all the necessary personnel and physical resources in close proximity. This proximity permits cancer patients to see multiple specialists on the same day, thereby reducing the time to treatment. Moreover, having multiple resources, such as radiation and infusion suites, in proximity permits patients to receive care without needing to travel long distances to a new facility. Proximity of providers also facilitates communication between specialists and helps to break down barriers between different departments (e.g., surgery and medical oncology) that serve as impediments to quality in medicine.

For these reasons, multidisciplinary clinics (MDC) are a hallmark of quality and patient-centered cancer care. Multidisciplinary clinics have been shown to reduce time to treatment, decrease number of visits, improve communication between teams, increase patient satisfaction, improve quality of life, and even improve survival [14]. 
Patients, families, and caregivers are at the heart of high-quality cancer care. High-quality cancer care should, therefore, ensure that the needs of the patients and their caregivers are met, which should include support in making informed decisions that are based on evidence-based medicine and, more importantly, align with patients' values and expectations. Cancer centers must assist their patients and families to comprehend the overall prognosis, benefits of treatments, and possible harms fully; provide palliative care, social support, and psychological support; and estimate cancer treatment costs accurately. In the setting of terminal cancer, resources that emphasize the importance of end-of-life care to maximize quality of life should be readily available.

Additionally, a structural hallmark of a high-quality cancer center are the professionals who provide care to patients. These include surgical, medical, and radiation oncologists, pathologists, palliative care physicians, oncology nurses, psychosocial workers, pharmacists, and other specialties that are routinely involved in providing cancer care. All providers should work together and effectively communicate, ensuring seamless transitions for patients and their families. All healthcare workers should also possess appropriate proficiencies and make appropriate treatment recommendations based on patients' and families' wishes. Roles should be clearly defined, and responsibilities assigned, with clear expectations from each member. There should be mutual trust between members, and communication should be effective. A cancer center should help continually improve communication skills among the staff with patients.

Health information technology systems also play an integral role in ensuring a high-quality cancer center. The electronic medical record (EMR) should be efficient and able to provide information to patients and healthcare providers in an effective manner, and it ideally should be structured to promote continuous improvement.

Finally, a cancer center needs a team of quality professionals_-including a physician lead, a nursing lead, and a nonphysician with a quality improvement background-who structurally comprise the core team that is tasked to help drive quality throughout the entire cancer center.

\section{Process}

Medical errors are common in medicine. A medical error is a preventable adverse effect of medical care, whether or not it is evident or harmful to the patient [15]. A 2013 study estimated that medical errors were the third leading cause of death in the United States, after heart disease and cancer, accounted for approximately 210,000 and 440,000 deaths annually [16]. The nine most common medical errors in the United States in 2014, in order of frequency, were adverse drug events, catheterassociated urinary tract infection (CAUTI), central line-associated bloodstream infection (CLABSI), injury from falls and immobility, obstetrical adverse events, pressure ulcers, surgical site infections (SSI), venous thrombosis (blood clots), and ventilator-associated pneumonia (VAP) [17]. 
The high complexity of cancer care and the morbidity of many cancer treatments greatly increase the potential for medical error, unfavorable outcomes, and system failure. Therefore, it is imperative for cancer centers to create a culture of safety, where all providers are expected to report and disclose errors due to the complexity of narrow therapeutic index of many cancer treatments. To support a culture of reporting medical errors, cancer centers should have an electronic reporting system in place that facilitates the reporting of adverse events by all members of the healthcare team. There should be a dedicated team comprised of physicians, nurses, and administrative staff who deal with adverse event reporting and are trained in performing root cause analyses. This electronic platform should help to identify trends over time, enabling quality improvement work.

Morbidity and mortality (M\&M) conferences are another vital tool that cancer centers should routinely use to improve overall quality of care [18]. These conferences provide a venue where errors and adverse events from individual cases can be discussed and process issues identified.

In addition to M\&M conferences, multidisciplinary tumor boards (MDTB) are an integral part of cancer care management, where experts from various domains of oncology discuss and present newly diagnosed patients. Research has shown that MDTBs lead to more accurate diagnosis, more accurate staging, and more appropriate treatments [19].

To ensure high-quality care, cancer centers must create a system of continuous improvement where key quality metrics are measured along the entire continuum of cancer care. An organization cannot consistently deliver quality products or services without creating a system that promotes continuous improvement as well as selfimprovement of employees. An organization cannot mandate excellence simply by slogans and unrealistic decrees by management [20].

Therefore, in order to hardwire quality and excellence, cancer center leadership must create an environment where processes are continuously improved, and those closest to the work are empowered to make changes that will lead to care of the highest possible quality for all patients. Continuous improvement is impossible without identification and measurement of key quality metrics. It is essential that those closest to the work (nurses, physicians, pharmacists, etc.), who are the content experts, help with deciding what key metrics to focus on and how best to measure them. Leadership is responsible with providing the infrastructure to measure key metrics and provide resources to permit continuous improvement of all cancer center processes with the goal of improving the quality of care for all patients.

Fortunately, American Society of Clinical Oncology (ASCO), National Comprehensive Cancer Network (NCCN), and international oncology organizations have developed a wealth of quality metrics for cancer centers to use, helping to simplify the work of selecting and defining metrics (Table 14.2). For example, NCCN advances its mission to improve and facilitate quality, effective, efficient, and accessible cancer care through creation and continuous update of clinical practice guideline, thereby facilitating creation of a reliable source for patients, clinicians, payers, and other healthcare decision-makers. Table 14.1 presents quality measures selected by NCCN's Quality and Outcomes Committee (Table 14.2). 
Table 14.1 Quality measures selected by the NCCN quality and outcomes committee [23]

\begin{tabular}{l|l}
\hline Cancer & Quality metrics \\
\hline Breast & $\begin{array}{l}\text { Patients should receive breast/chest wall plus regional lymph node radiation if they } \\
\text { have M0 disease or involvement of } \geq 4 \text { axillary lymph nodes. }\end{array}$ \\
\hline Breast & $\begin{array}{l}\text { Patients who have been cured of breast cancer should not have tumor markers } \\
\text { performed during the follow-up surveillance period. }\end{array}$ \\
\hline Colorectal & $\begin{array}{l}\text { Patients with rectal cancer should undergo staging CT chest, abdomen, pelvis and } \\
\text { pelvic MRI with contrast or endorectal ultrasound before surgery. }\end{array}$ \\
\hline Colorectal & $\begin{array}{l}\text { Carcinoembryonic antigen should be performed every } 6 \text { months for 5 years for } \\
\text { patients with resected pathological stage II and III colorectal cancer. }\end{array}$ \\
\hline Lung & $\begin{array}{l}\text { Patients with newly diagnosed metastatic non-small cell lung cancer should have a } \\
\text { palliative medicine consult within 8 weeks of diagnosis. }\end{array}$ \\
\hline Prostate & $\begin{array}{l}\text { All patients in high-risk prostate cancer group who undergo radiation should be } \\
\text { treated with androgen deprivation therapy. }\end{array}$ \\
\hline Prostate & $\begin{array}{l}\text { Patients who have undergone surgery or radiation for localized prostate cancer } \\
\text { should be evaluated for sexual dysfunction and urinary incontinence. }\end{array}$ \\
\hline Prostate & $\begin{array}{l}\text { Patients with prostate cancer should have prostate specific antigen measured every } \\
12 \text { months to monitor recurrence of disease. }\end{array}$ \\
\hline $\begin{array}{l}\text { Cross- } \\
\text { cancer }\end{array}$ & $\begin{array}{l}\text { Cancer stage should be documented. } \\
\text { Performance status should be documented before starting systemic therapy. } \\
\text { Percentage of patients with cancer admitted to intensive care unit in the last } \\
\text { 30 days of life. } \\
\text { Patients who smoke should be offered smoking cessation counselling. } \\
\text { Number of patients undergoing chemotherapy in the last 14 days of life. } \\
\text { Number of patients dying from cancer in the acute care setting. } \\
\text { Chemotherapy given within 30 days of end of life. }\end{array}$ \\
\hline
\end{tabular}

\section{Outcome}

In medicine, there is a much greater focus on outcomes than processes. This is understandable, since the overall goal of treating any cancer is ultimately cure. However, any outcome is the culmination of many processes, and improving an outcome is nearly impossible without a thorough understanding of all the processes involved that led to a specific outcome. Take, for example, the diagnosis and subsequent treatment of early stage breast cancer. This involves many processes, including breast cancer screening, radiographic interpretation, biopsy of suspicious lesions, pathologic interpretation, surgical management, selection of appropriate chemo- and endocrine therapy, radiation oncology, management of treatmentrelated toxicities, and cancer survivorship. Five-year breast cancer survival is a culmination of all of these processes, as well as others. To improve this outcome metric requires identification of key improvements in many or all of these processes.

This is not to say that outcome measures are not important. Indeed, they are extremely important. However, outcomes cannot be viewed as independent of processes, since they are completely dependent on them. Additionally, survival outcomes for a cancer center cannot be viewed in isolation of the populations that they serve. Population and socioeconomic factors can influence survival, independent of quality of medical care. For example, breast cancer mortality has been shown to correlate positively with socioeconomic factors that vary quite substantially across 
Table 14.2 Selected resources on cancer care quality

\begin{tabular}{|c|c|c|}
\hline Organization & Description & Link \\
\hline $\begin{array}{l}\text { American Academy of } \\
\text { hospice and palliative } \\
\text { medicine (AAHPM) }\end{array}$ & $\begin{array}{l}\text { Resources and tools to address quality } \\
\text { and patient safety in hospice and } \\
\text { palliative care setting }\end{array}$ & $\begin{array}{l}\text { http://aahpm.org/ } \\
\text { education/quality }\end{array}$ \\
\hline $\begin{array}{l}\text { American Society of } \\
\text { Clinical Oncology } \\
\text { (ASCO) }\end{array}$ & $\begin{array}{l}\text { Information on ASCO quality programs, } \\
\text { guidelines, chemotherapy safety } \\
\text { standards, and quality oncology practice } \\
\text { initiative (QOPI), and registry } \\
\text { (CancerLinQ) }\end{array}$ & $\begin{array}{l}\text { https://practice.asco.org/ } \\
\text { quality-improvement }\end{array}$ \\
\hline $\begin{array}{l}\text { American Society of } \\
\text { Hematology (ASH) }\end{array}$ & $\begin{array}{l}\text { Quality care resources specific to } \\
\text { nonmalignant and malignant hematologic } \\
\text { diseases }\end{array}$ & $\begin{array}{l}\text { https://www.hematology. } \\
\text { org/education/clinicians/ } \\
\text { guidelines-and-quality- } \\
\text { care }\end{array}$ \\
\hline $\begin{array}{l}\text { American Society for } \\
\text { Radiation Oncology } \\
\text { (ASTRO) }\end{array}$ & $\begin{array}{l}\text { List of quality measures specific to } \\
\text { radiation oncology }\end{array}$ & $\begin{array}{l}\text { https://www.astro.org/ } \\
\text { Daily-Practice/QPP/ } \\
\text { Measures/Inventory }\end{array}$ \\
\hline $\begin{array}{l}\text { Commission on Cancer } \\
(\mathrm{CoC})\end{array}$ & $\begin{array}{l}\text { Information on } \mathrm{CoC} \text { standards to facilitate } \\
\text { quality cancer care delivery }\end{array}$ & $\begin{array}{l}\text { https://www.facs.org/ } \\
\text { quality-programs/cancer/ } \\
\text { coc }\end{array}$ \\
\hline $\begin{array}{l}\text { Foundation for the } \\
\text { Accreditation of cellular } \\
\text { therapy (FACT) }\end{array}$ & $\begin{array}{l}\text { Quality standards for hematopoietic cell } \\
\text { transplantation and cellular therapies }\end{array}$ & $\begin{array}{l}\text { http://www.factwebsite. } \\
\text { org/ }\end{array}$ \\
\hline $\begin{array}{l}\text { American College of } \\
\text { Surgeons (ACS) }\end{array}$ & $\begin{array}{l}\text { National Accreditation Program for breast } \\
\text { centers (NAPBC) }\end{array}$ & $\begin{array}{l}\text { https://www.facs.org/ } \\
\text { Quality-Programs/ } \\
\text { NAPBC/Standards }\end{array}$ \\
\hline $\begin{array}{l}\text { National Comprehensive } \\
\text { Cancer Network } \\
(\mathrm{NCCN})\end{array}$ & $\begin{array}{l}\text { List of high-priority and high-impact } \\
\text { cancer quality measures proposed by } \\
\text { NCCN }\end{array}$ & $\begin{array}{l}\text { https://jnccn.org/view/ } \\
\text { journals/jnccn/18/3/ } \\
\text { article-p250.xml }\end{array}$ \\
\hline $\begin{array}{l}\text { National Quality Forum } \\
\text { (NQF) }\end{array}$ & $\begin{array}{l}\text { Cancer care quality measures endorsed by } \\
\mathrm{NQF}\end{array}$ & $\begin{array}{l}\text { http://www.qualityforum. } \\
\text { org/Cancer.aspx }\end{array}$ \\
\hline $\begin{array}{l}\text { Oncology Nursing } \\
\text { Society (ONS) }\end{array}$ & ONS resources on quality cancer care & $\begin{array}{l}\text { https://www.ons.org/ } \\
\text { make-difference/ } \\
\text { quality-improvement }\end{array}$ \\
\hline
\end{tabular}

countries and that are associated with economic development and social/lifestyle factors [21].

In order to measure long-term cancer outcomes, cancer centers need to have a robust tumor registry that can track outcomes among the cancer patients that they serve. These long-term outcomes would need to be stratified to factor in medical comorbidities and socioeconomic factors. Ideally, these data should be benchmarked to national data if available. This would require statistical and epidemiologic support that may not be readily available to all cancer centers but would be of great value, particularly when thinking about where the greatest opportunities are for improvement of cancer outcomes.

Patient satisfaction is also an important outcome that cancer centers must reliably track. Validated patient questionnaires that are provided to patients and their families are a key way to capture the voice of the patient and to identify areas of strength and areas where improvements must be made. Creating a culture of patientcentered care requires honest feedback from patients. 
Another important outcome measure is patient-reported outcomes (PROs). Symptoms are common among patients receiving treatment for advanced cancers yet are undetected by clinicians up to half the time. There is growing interest in integrating electronic PROs into routine oncology practice for symptom monitoring. In a recent randomized trial, data integration of PROs into the routine care of patients with metastatic cancer was associated with a significant improvement in overall survival compared with usual care [22]. Earlier identification of emerging toxicities in patients enabled the oncology care team to intervene more rapidly before toxicities became more severe, enabling patients to stay on treatments longer and avoid unnecessary hospitalizations.

\section{Conclusions}

Quality in healthcare has three primary domains: structure, process, and outcome. This is the three-legged stool upon which clinical excellence sits. To successfully build quality from the ground up in a cancer center, first you need the right people. A quality team of professionals that is responsible for promoting a culture of excellence and quality improvement is needed. This small team should be comprised of physicians, nurses, pharmacists, data management, and quality improvement professionals. Responsibility should be delegated by executive leadership to this quality team to drive quality and foster a culture of quality improvement throughout the entire cancer center. High-quality care is synonymous with patient-centered care and is everyone's responsibility. Those who are closest to the patient and, therefore, have the greatest control over treatment decisions must be given the proper tools, education, and support to conduct quality improvement activities. Providers need access to timely data on relevant quality-related process and outcome measures, because improvement is practically impossible without formal longitudinal measurements. Fortunately, there are a wealth of validated oncology quality measures that have been created by ASCO, NCCN, and other organizations, which cancer centers can adapt.

\section{References}

1. Donabedian A. Evaluating the quality of medical care. Milbank Q. 2005;83(4):691-729. https://doi.org/10.1111/j.1468-0009.2005.00397.x.

2. Donabedian A. Explorations in quality assessment and monitoring. Health Administration Press; Ann Arbor, 1985.

3. Donabedian A. The seven pillars of quality. Arch Pathol Lab Med. 1990;114(11):1115-8.

4. Ayanian JZ, Markel H. Donabedian's lasting framework for health care quality. N Engl J Med. 2016;375(3):205-7. https://doi.org/10.1056/NEJMp1605101.

5. Institute of Medicine. Medicare: a strategy for quality assurance. National Academies Press; 1990. https://doi.org/10.17226/1547.

6. Institute of Medicine. Ensuring quality cancer care. National Academies Press; 1999. https:// doi.org/10.17226/6467.

7. Institute of Medicine. Crossing the quality chasm: a new health system for the 21 st century. National Academies Press; 2001. https://doi.org/10.17226/10027. 
8. Institute of Medicine. Performance measurement: accelerating improvement. National Academies Press; 2006. https://doi.org/10.17226/11517.

9. Park J, Look KA. Health care expenditure burden of cancer care in the United States. Inq J Heal Care Organ Provision, Financ. 2019;56:004695801988069. https://doi. org/10.1177/0046958019880696.

10. Mariotto AB, Enewold L, Zhao J, Zeruto CA, Yabroff KR. Medical care costs associated with cancer survivorship in the United States. Cancer Epidemiol Biomark Prev. 2020;29(7):1304-12. https://doi.org/10.1158/1055-9965.EPI-19-1534.

11. Global Cancer Observatory. Cancer incidence in five continents time trends. Published 2020. Accessed July 4, 2020. https://ci5.iarc.fr/CI5plus/Pages/graph4_sel.aspx.

12. Araghi M, Soerjomataram I, Jenkins M, et al. Global trends in colorectal cancer mortality: projections to the year 2035. Int J Cancer. 2019;144(12):2992-3000. https://doi.org/10.1002/ijc.32055.

13. Levit L, Balogh E, Nass S, Ganz P, editors. Delivering high-quality cancer care: charting a new course for a system in crisis. Institute of Medicine; Washington (DC), 2013.

14. Horvath LE, Yordan E, Malhotra D, et al. Multidisciplinary care in the oncology setting: historical perspective and data from lung and gynecology multidisciplinary clinics. J Oncol Pract. 2010;6(6):e21-6. https://doi.org/10.1200/JOP.2010.000073.

15. Hofer TP, Kerr EA, Hayward RA. What is an error? Eff Clin Pract. 2000;3(6):261-9.

16. Makary MA, Daniel M. Medical error: the third leading cause of death in the US. BMJ. Published online May 2016:i2139. doi:https://doi.org/10.1136/bmj.i2139.

17. Carver N, Gupta V, Hipskind JE. Medical Error; 2020. In: StatPearls [Internet]. Treasure Island (FL): StatPearls Publishing; 2021. PMID: 28613514. Bookshelf ID: NBK430763.

18. Stover DG, Zerillo JA. Morbidity and mortality revisited: applying a new quality improvement paradigm in oncology. J Oncol Pract. 2015;11(3):e428-32. https://doi.org/10.1200/ JOP.2014.003566.

19. Specchia ML, Frisicale EM, Carini E, et al. The impact of tumor board on cancer care: evidence from an umbrella review. BMC Health Serv Res. 2020;20(1):73. https://doi.org/10.1186/ s12913-020-4930-3.

20. Gitlow H, Oppenhein A, Oppenheim R, Levine D. Quality management. 3rd ed. McGraw-Hill; New York, 2005.

21. Ji P, Gong Y, Jiang C, Hu X, Di G, Shao Z. Association between socioeconomic factors at diagnosis and survival in breast cancer: a population-based study. Cancer Med. 2020;9(5):1922-36. https://doi.org/10.1002/cam4.2842.

22. Basch E, Deal AM, Dueck AC, et al. Overall survival results of a trial assessing patient-reported outcomes for symptom monitoring during routine Cancer treatment. JAMA. 2017;318(2):197. https://doi.org/10.1001/jama.2017.7156.

23. D'Amico TA, Bandini LAM, Balch A, et al. Quality measurement in cancer care: a review and endorsement of high-impact measures and concepts. JNCCN J Natl Compr Cancer Netw. 2020;18(3):250-9. https://doi.org/10.6004/jnccn.2020.7536.

Open Access This chapter is licensed under the terms of the Creative Commons Attribution 4.0 International License (http://creativecommons.org/licenses/by/4.0/), which permits use, sharing, adaptation, distribution and reproduction in any medium or format, as long as you give appropriate credit to the original author(s) and the source, provide a link to the Creative Commons license and indicate if changes were made.

The images or other third party material in this chapter are included in the chapter's Creative Commons license, unless indicated otherwise in a credit line to the material. If material is not included in the chapter's Creative Commons license and your intended use is not permitted by statutory regulation or exceeds the permitted use, you will need to obtain permission directly from the copyright holder.

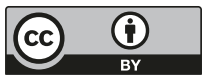

